\title{
A pragmatic approach for the downscaling and bias correction of regional climate simulations: evaluation in hydrological modeling
}

\author{
T. Marke ${ }^{1}$, W. Mauser ${ }^{2}$, A. Pfeiffer ${ }^{3}$, and G. Zängl ${ }^{4}$ \\ ${ }^{1}$ Department of Geography, Karl-Franzens University, Graz, Austria \\ ${ }^{2}$ Department of Geography, Ludwig-Maximilians University, Munich, Germany \\ ${ }^{3}$ Meteorological Institute, Ludwig-Maximilians University, Munich, Germany \\ ${ }^{4}$ Deutscher Wetterdienst, Offenbach, Germany
}

Received: 29 November 2010 - Published in Geosci. Model Dev. Discuss.: 8 January 2011

Revised: 1 September 2011 - Accepted: 2 September 2011 - Published: 7 September 2011

\begin{abstract}
The present study investigates a statistical approach for the downscaling of climate simulations focusing on those meteorological parameters most commonly required as input for climate change impact models (temperature, precipitation, air humidity and wind speed), including the option to correct biases in the climate model simulations. The approach is evaluated by the utilization of a hydrometeorological model chain consisting of (i) the regional climate model MM5 (driven by reanalysis data at the boundaries of the model domain), (ii) the downscaling and model interface SCALMET, and (iii) the physically based hydrological model PROMET. The results of different hydrological model runs set up for the historical period 1971-2000 are compared to discharge recordings at the gauge of the Upper Danube Watershed (Central Europe) on a daily time basis. To avoid "in-sample" evaluation, a cross-validation approach is followed splitting the period in two halves of $15 \mathrm{yr}$. While one half is utilized to derive the downscaling functions based on spatially distributed observations (e.g. 19711985), the other is used for the application of the downscaling functions within the hydrometeorological model chain (e.g. 1986-2000). By alternately using both parts for the generation and the application of the downscaling functions, discharge simulations are generated for the whole period 19712000. The comparison of discharge simulations and observations reveals that the presented approaches allow for a more accurate simulation of discharge in the catchment of the Upper Danube Watershed and the considered gauge at the outlet in Achleiten. The correction for subgrid-scale variability is shown to reduce biases in simulated discharge compared to the utilization of bilinear interpolation. Further enhance-
\end{abstract}

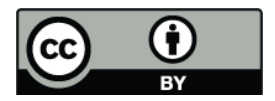

Correspondence to: T. Marke (thomas.marke@uni-graz.at) ments in model performance could be achieved by a correction of biases in the RCM data within the downscaling process. These findings apply to the cross-validation experiment as well as to an "in-sample" application, where the whole period 1971-2000 is used for the generation and the application of the downscaling functions. Although the presented downscaling approach strongly improves the performance of the hydrological model, deviations from the observed discharge conditions persist that are not found when driving the hydrological model with spatially distributed meteorological observations.

\section{Introduction}

Regional climate models (RCMs) have been used in a variety of studies to refine climate simulations or coarsely resolved (re-)analysis data from the global to the regional scale (Kotlarski et al., 2005; Jacob et al., 2007; Pfeiffer and Zängl, 2010). The resulting regional climate information is often utilized as input for models operating at the land surface, e.g. snow models (Lazar and Williams, 2008) or hydrological models (Wood et al., 2004; Marke, 2008), in many cases with the aim to analyze climate change impacts at the land surface. However, the dynamical downscaling of global climate simulations or datasets by means of present generation RCMs is still computationally limited to spatial resolutions in the order of $10 \times 10 \mathrm{~km}$. Several techniques for a further refinement of climate simulations have been proposed and applied over the last two decades. Wilby and Wigley (1997) give an overview of downscaling techniques, divided into four different basic classes: regression methods, weather pattern approaches, stochastic weather generators and so-called limited area (i.e. regional) models. Fowler et al. (2007) follow these

Published by Copernicus Publications on behalf of the European Geosciences Union. 
definitions in their extensive review on the performance of different downscaling approaches in the view of hydrological modelling. Regression methods rely on linear or non-linear relationships between the subgrid-scale parameters (the predictands) and coarse-grid variables generated by an atmospheric model (the predictors). Widmann et al. (2003) find a good performance using precipitation itself as predictor for the downscaling of precipitation. This, however, requires a realistically simulated coarse-scale precipitation, a prerequisite that should be reasonably fulfilled by a state-of-the-art $\mathrm{RCM}$. A prerequisite for a weather pattern approach is a systematic classification of typical large-scale atmospheric (circulation) patterns as subjectively pooled, for example, to a catalogue of European "Grosswetterlagen" by Gerstengarbe et al. (1999). These patterns are statistically related to observed values of the considered meteorological variable to give probability distribution functions that can be applied to downscale corresponding sequences of synoptic situations generated by a meteorological model. Statistic weather generators (e.g. Watts et al., 2004) are commonly based on firstup to third-order Markov chains; they tend, however, to show deficiencies in building physically realistic and consistent data under changing climate conditions.

As the computational demand of RCMs is quite substantial, a further dynamical refinement of RCM output with an additional, subsequent RCM simulation to a horizontal resolution at the order of $\sim 1 \mathrm{~km}$ is not feasible on climatological time scales, at least with today's resources. Most statistical methods are comparatively inexpensive in terms of computational resources what can be a major practical advantage in many applications. However, the preparation and analysis of empirical data, such as pattern analysis, required by some statistical methods, can be quite intricate and complex. Many statistical or empirical methods, due to their very design, only produce data valid in a climatological sense. It is most desirable, however, to devise downscaling approaches that allow for applications and comparison to observations on a daily time basis, particularly in hydrological studies.

Beside the scale mismatch in the spatial resolutions of RCMs and impact models, the application of RCM data in climate change impact studies is often hampered by biases in the simulations quantified by a comparison of RCM data to measured values (e.g. biases in simulated temperature and precipitation). Kotlarski et al. (2005) have compared simulations conducted with a large set of RCMs to different observation-based datasets for the area of Germany on a monthly time basis. Their studies reveal biases that largely depend on the chosen RCM, the geographical region and the observation-based meteorological reference data.

Many studies have been carried out in the past in order to analyze biases in RCM simulations (e.g. Kotlarski et al., 2005; Jacob et al., 2007; Pfeiffer and Zängl, 2010) or the performance of downscaling techniques, mainly with focus on highly resolved spatial distributions of temperature and precipitation on a daily basis (e.g. Leung et al., 2003; Früh et al., 2006). However, existing studies often concentrate on the meteorological analysis of downscaling efficiency and do not consider their implications on the results of models operating at the land surface. The current study aims at increasing the potential of RCM simulations in climate change impact analysis by the development of simple and pragmatic downscaling techniques that are applicable for a range of meteorological parameters required for impact modeling. A downscaling method is designed and evaluated that is to be implemented in a most straightforward manner while being extremely effective in terms of computational costs. This should allow for its "online" use in complex climate impact model compounds, such as developed within the project GLOWA-Danube (www.glowa-danube.de). Here, downscaling approaches are required that can be applied to translate between the scale of RCMs (grid size $\geq 10 \mathrm{~km}$ ) and land surface models (grid size $=1 \mathrm{~km}$ ) on an hourly time basis. As climate change impact models should avoid calibration, biases in the meteorological input (in terms of deviations from observations) severely affect the accuracy of the impact models. Hence, downscaling methods not only need to be computationally efficient to allow long term simulations over decades to centuries, but need to be in line with the high demands of physically based process models on the quality of the meteorological input. The methods evaluated in this study are based on a pragmatic downscaling approach for precipitation developed by Früh et al. (2006). Furthermore, an approach is investigated that allows the correction of biases in various meteorological parameters within the downscaling process. Both, the meteorological simulations used in our study, as well as the statistical downscaling applied, have been meteorologically evaluated in different studies in the past (e.g. Früh et al., 2007; Schipper et al., 2010). Our study focuses on a hydrological evaluation of the presented downscaling approaches. A hydrometeorological model chain is set up for the period 1971-2000 in order to analyze the effect of downscaling on river runoff simulations in the Upper Danube Watershed (Central Europe). It is composed of (i) the regional climate model MM5 (Grell et al., 1994) which is driven by ERA40 reanalysis data (Uppala et al., 2005) at its lateral boundaries, (ii) the downscaling and model interface SCALMET (Marke, 2008), and (iii) the process-based distributed hydrological model PROMET (Mauser and Bach, 2009). The hydrological model has high demands with respect to the meteorological input data. It requires high temporal $(1 \mathrm{~h})$ and spatial resolution $(1 \mathrm{~km})$ as well as a total number of seven meteorological parameters (precipitation, temperature, wind speed, air humidity, incoming shortwave and longwave radiation, surface pressure) for the process description at the land surface. The results of the hydrological model are evaluated on a daily time basis by comparing the discharge simulated for the outlet of the Upper Danube Watershed at Achleiten to discharge recordings. 


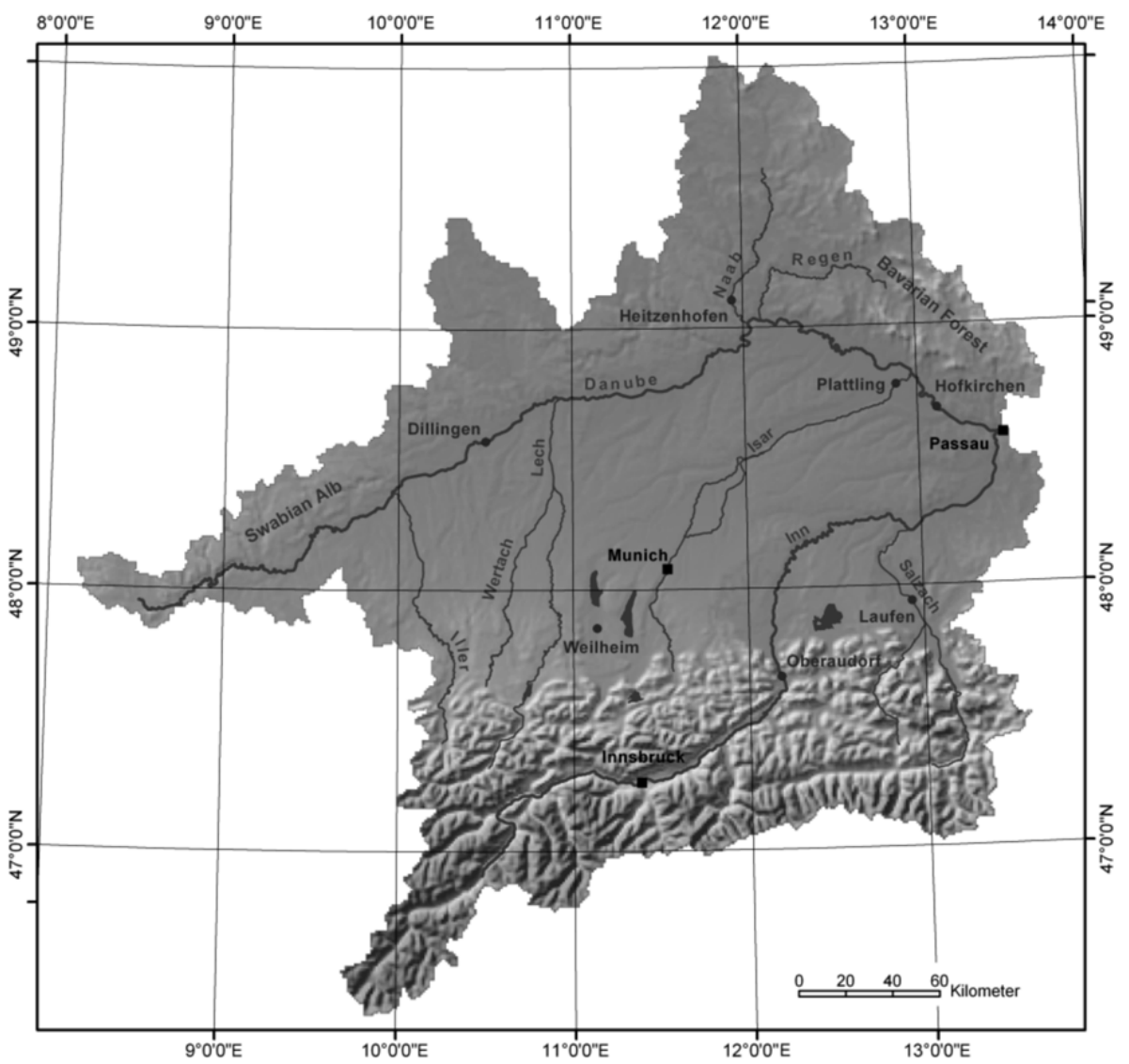

Fig. 1. The Upper Danube Watershed.

\section{Study site}

The current study has been conducted in the Upper Danube River Basin, a mountainous watershed situated in Central Europe, covering an area of $76653 \mathrm{~km}^{2}$ and territories in southern Germany, Austria, Switzerland, the Czech Republic and Italy (Fig. 1). The complex topography is characterized by a large gradient of altitude reaching from $287 \mathrm{~m}$ a.m.s.l. at the discharge gauge of the watershed at Achleiten up to $4049 \mathrm{~m}$ a.m.s.l. at Piz Bernina in the Alpine headwaters. This altitudinal gradient leads to strong meteorological gradients. Annual precipitation ranges from 550 to $>2000 \mathrm{~mm}$, annual mean temperatures from -4.8 to $9{ }^{\circ} \mathrm{C}$, evapotranspiration from 100 to $700 \mathrm{~mm}$ per $\mathrm{yr}$ and the resulting annual discharge from 150 to $1750 \mathrm{~mm}$ per yr (Mauser and Bach, 2009). The majority of the Upper Danube's tributaries emerge in higher altitudes of the Alps and cross the lowlands towards the north in advance of their confluence with the Danube. The Danube leaves the watershed in a west to east direction in the northern part of the basin at the gauge in Achleiten (near Passau).

\section{Methods}

\subsection{Models}

The hydrometeorological model chain used in the current study is composed of four coupled components (see Fig. 2). The ERA40 reanalysis (Uppala et al., 2005) supplies the global meteorological data that are dynamically downscaled to a spatial resolution of $45 \times 45 \mathrm{~km}$ by the Pennsylvania State University/National Center for Atmospheric Research Mesoscale Model MM5 (release 3.7.3) (Grell et al., 1994). MM5 has been set up for an area of about $3000 \times 3500 \mathrm{~km}$ in the current study. Covering most of the European continent (see Fig. 3), the size of the model domain allows to capture all relevant synoptic-scale phenomena governing the climate in our region of interest. The optimal configuration of MM5 with focus on an accurate simulation of precipitation in southern Germany and the northern Alps, has been identified by Pfeiffer and Zängl (2010) on the basis of a ten year simulation of the 1990s driven with ERA40 data. In the current setup, atmospheric processes are described for 29 vertical layers with level intervals increasing from the boundary layer to the higher atmosphere up to a top lid pressure of $100 \mathrm{hPa}$. 


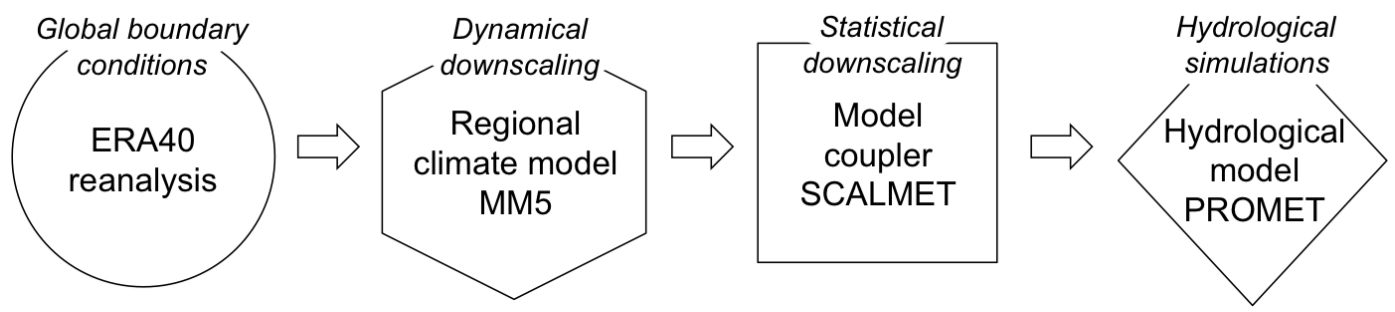

Fig. 2. Schematic overview of the hydrometeorological model chain.

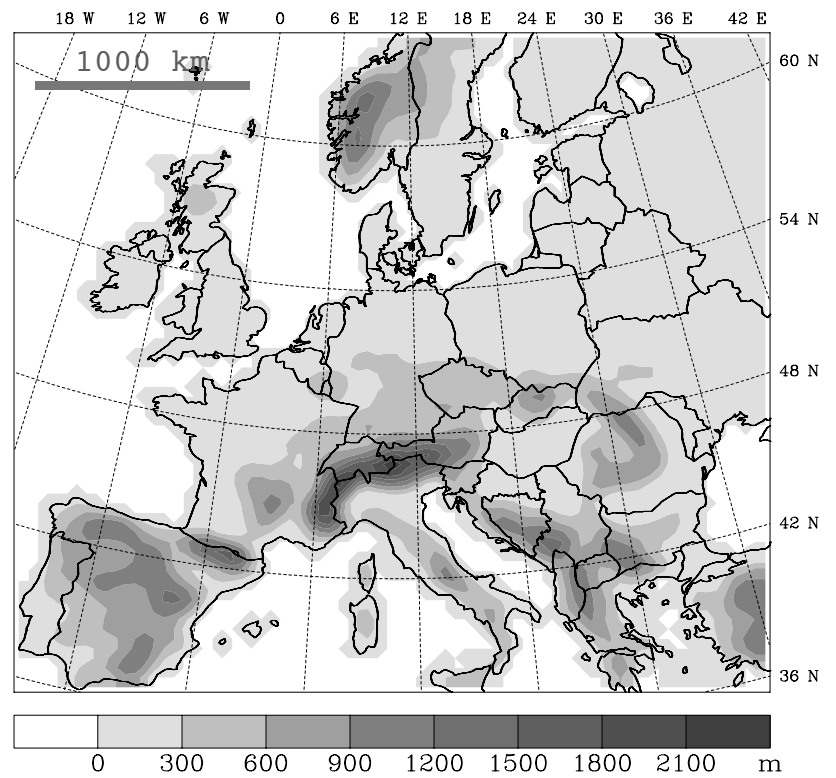

Fig. 3. Model domain and model topography of the regional climate model MM5 (for this illustration topography is interpolated from $45 \times 45 \mathrm{~km}$ spatial resolution).

The dynamical downscaling by MM5 is followed by a statistical downscaling performed within the model coupler and scaling tool SCALMET (Marke, 2008). SCALMET has been designed in the framework of the GLOWA-Danube project to allow for the analysis of climate change impacts on the water balance of the Upper Danube Watershed by performing a synchronized exchange of energy and water fluxes between meteorological and land surface models. As the downscaling in SCALMET is carried out during the runtime of the model system, the complexity of the applied downscaling techniques is strongly limited. In our study the coupler applies statistical downscaling functions with and without bias correction to translate from the RCM scale $(45 \times 45 \mathrm{~km})$ to the scale of the hydrological simulations $(1 \times 1 \mathrm{~km})$. Hydrological modelling is carried out with the distributed, physically based hydrological model PROMET (Processes of Radiation, Mass and Energy Transfer) (Mauser and Bach, 2009). PROMET was initially designed by Mauser and
Schädlich (1998) as a SVAT-type evapotranspiration model that has been applied at different spatial scales ranging from single field scale to mesoscale watersheds $\left(100000 \mathrm{~km}^{2}\right)$ and under a variety of climatological conditions (Bach et al., 2003; Strasser and Mauser, 2001; Ludwig and Mauser, 2000). Details on the hydrological model PROMET, the different model components and model validation can be found in Mauser and Bach (2009).

\subsection{Downscaling approach}

The two statistical downscaling approaches applied to correct for subgrid-scale variability and bias have both initially been developed for the downscaling of precipitation in a complex, Alpine terrain (Früh et al., 2006). The general concepts of the approaches, however, should be applicable for the downscaling of temperature, wind speed and air humidity as well. The approach is based on the application of a downscaling function for every month of the year and is described in detail in the following paragraphs. To clearly distinguish between the participating grid resolutions, the coarse RCM grid $(45 \times 45 \mathrm{~km})$ is referred to by capital letters, whereas the fine resolution of the hydrological model $(1 \times 1 \mathrm{~km})$ is referred to by small letters.

In a first step, the subgrid-scale variability is estimated with respect to the RCM grid for a given meteorological parameter and a given month of the year on the basis of a high resolution observed climatology $\mathrm{x}_{\mathrm{obs}}(\mathrm{m})$, where $\mathrm{x}$ stands for the meteorological parameter and $\mathrm{m}$ for the considered month. The term "subgrid-scale variability" as used in this paper is related to the spatial variability of a given meteorological parameter within the area covered by a coarse grid cell (here $45 \times 45 \mathrm{~km}$ ) and not to temporal variability. The high resolution climatology used here covers the period 1971-2000 and is generated by the meteorological preprocessor in the hydrological model PROMET as described in detail by Mauser and Bach (2009). In this model component, spatial distributions of temperature, precipitation, humidity and wind speed are generated by making use of existing parameter-elevation dependencies, an approach applied and validated in a number of studies in the past (e.g. Cosgrove et al., 2003; Liston and Elder, 2006). In PROMET, a parameter-elevation function is derived from the station 
recordings via linear regression and is then applied to the pixel heights of a digital elevation model. This step is followed by an inverse distance weighted interpolation of the residuals at the station locations. Wege (1998) and Hank et al. (2007) have cross-validated this approach by comparing interpolated and observed values at selected station locations in the Upper Danube Watershed. Both authors come to the conclusion that the regression-based method allows to accurately reproduce the meteorological conditions at the stations for the individual time periods considered. As precipitation distributions are characterized by complex patterns that are induced by luff-lee effects and orographic lifting at the northern rim of the Alps, daily correction factors are applied that have been generated by using the Parameter-elevation Regression on Independent Slope Model (PRISM) (Daly et al., 1994) on the basis of a 10-yr analysis of over 2000 rainfall gauges.

For the generation of the downscaling functions applied in this paper, the mean monthly patterns generated from hourly maps of meterological parameters as derived by the PROMET preprocessor are aggregated from $1 \times 1 \mathrm{~km}$ to the grid structure and spatial resolution of the RCM. The upscaling to the RCM grid resolution is done by calculating the area weighted mean of all high resolution grid cells $x_{\mathrm{obs}}(\mathrm{m})$ that are completely or partially within the respective coarse resolution cell $X_{\mathrm{obs}}(\mathrm{m})$.

The coarse grid cells $X_{\text {obs }}(\mathrm{m})$ are subsequently bilinearly interpolated to generate the high resolution grid. The individual cells of the resulting grid are denoted here as $x_{\text {obs_bil }}(\mathrm{m})$.

A downscaling function $F_{\text {vari }}(\mathrm{m})$ is finally calculated as:

$F_{\text {vari }}(\mathrm{m})=x_{\text {obs }}(\mathrm{m}) / x_{\text {obs_bil }}(\mathrm{m})$

Applying this statistical downscaling approach for the remapping of RCM data considers the subgrid-scale variability of a given meteorological parameter while the mass and energy budgets imposed by the RCM simulations $X_{\text {sim }}(\mathrm{h})$ are conserved for each hourly output-time step $h$. Please note that this conservation of mass and energy applies to the area of the RCM grid cells and not necessarily to the area of the considered catchment. The approach is referred to by the abbreviation vari in the course of this study.

As biases in terms of deviations from observed climatological conditions exist in simulations of present-generation RCMs, the quality of physically based hydrological simulations is expected to be compromised by an application of uncorrected RCM simulations as meteorological input. Studies by Kotlarski et al. (2005) focusing on the area of Germany have revealed deviations between RCM simulations and observation-based meteorological data of up to $2{ }^{\circ} \mathrm{C}$ for mean annual temperature and of more than $50 \%$ for mean annual precipitation. Note, however, that the quality of the station recordings and their processing also need to be taken into account (Hagemann et al., 2001; Kotlarski et al., 2005; Pfeiffer and Zängl, 2010). As recordings in Alpine areas are predominantly taken in valleys rather than on mountain ridges, simple areal averages can be expected to be systematically biased and correction algorithms involve substantial uncertainty (Pfeiffer and Zängl, 2010). Furthermore, precipitation recordings suffer from a wind-induced underestimation of solid precipitation, especially in mountainous terrain (Sevruk, 1985). In our case, none of the systematic errors described above have been corrected prior to an application of the data.

Not all biases in RCM simulations can be compensated for by the consideration of subgrid-scale variability and the related redistribution of mass and energy within a given RCM grid box. Früh et al. (2006) show that RCMs often fail to accurately simulate the complex precipitation patterns in the Alps, which are characterized by precipitation maxima at the northern and southern rim of the Alps, whereas the inner Alpine valleys are comparatively dry (Frei and Schär, 1998). As shown by Wilby et al. (2000) and Marke (2008) the sensitivity of hydrological models to biases in climate simulations is particularly severe in Alpine watersheds, where the seasonal storage of water in the snowpack controls to a large degree the discharge at the outlet of the watersheds.

To correct RCM simulations beyond the scope of a redistribution of mass and energy within a given climate model grid box, a further processing step has been developed and integrated into SCALMET. Following Murphy (1999) and Früh et al. (2006) an empirical adjustment of RCM data based on local climate statistics is carried out by calculating a bias correction $F_{\text {bias }}(\mathrm{m})$ in form of:

$F_{\text {bias }}(\mathrm{m})=x_{\text {obs_bil }}(\mathrm{m}) / x_{\text {sim_bil }}(\mathrm{m})$

where $x_{\text {obs_bil }}(\mathrm{m})$ are the aggregated monthly observations for the period 1971-2000 and $\mathrm{x}_{\text {sim_bil }}(\mathrm{m})$ are the mean monthly simulation results for the period 1971-2000, both bilinearly interpolated from the coarse to the fine grid. Combining the terms for the consideration of subgridscale variability and bias correction a downscaling function $F_{\text {vari\&bias }}(\mathrm{m})$ is calculated as:

$F_{\text {vari\&bias }}(\mathrm{m})=F_{\text {vari }}(\mathrm{m}) \cdot F_{\text {bias }}(\mathrm{m})$

This downscaling function leads to a redistribution of the meteorological parameter considered at the catchment scale deliberately accepting a possible "breach" of the mass and energy budget. It is referred to by the abbreviation vari\&bias in the following.

The functions $F_{\text {vari }}(\mathrm{m})$ and $F_{\text {vari\&bias }}(\mathrm{m})$ as derived under (1) and (3) are calculated for the parameters precipitation, wind speed and humidity in advance of the coupled model runs and then are used within the downscaling process in SCALMET to multiply the bilinearly interpolated RCM simulations $\mathrm{x}_{\text {sim_bil }}(\mathrm{h})$ at each hourly time step $\mathrm{h}$. As relative humidity is a function of air water content and air temperature, the remapping of humidity is carried out on the basis of absolute air humidity. The downscaled absolute humidity is later converted to relative humidity making use of the downscaled air temperature. Thereby, quality checks are carried 

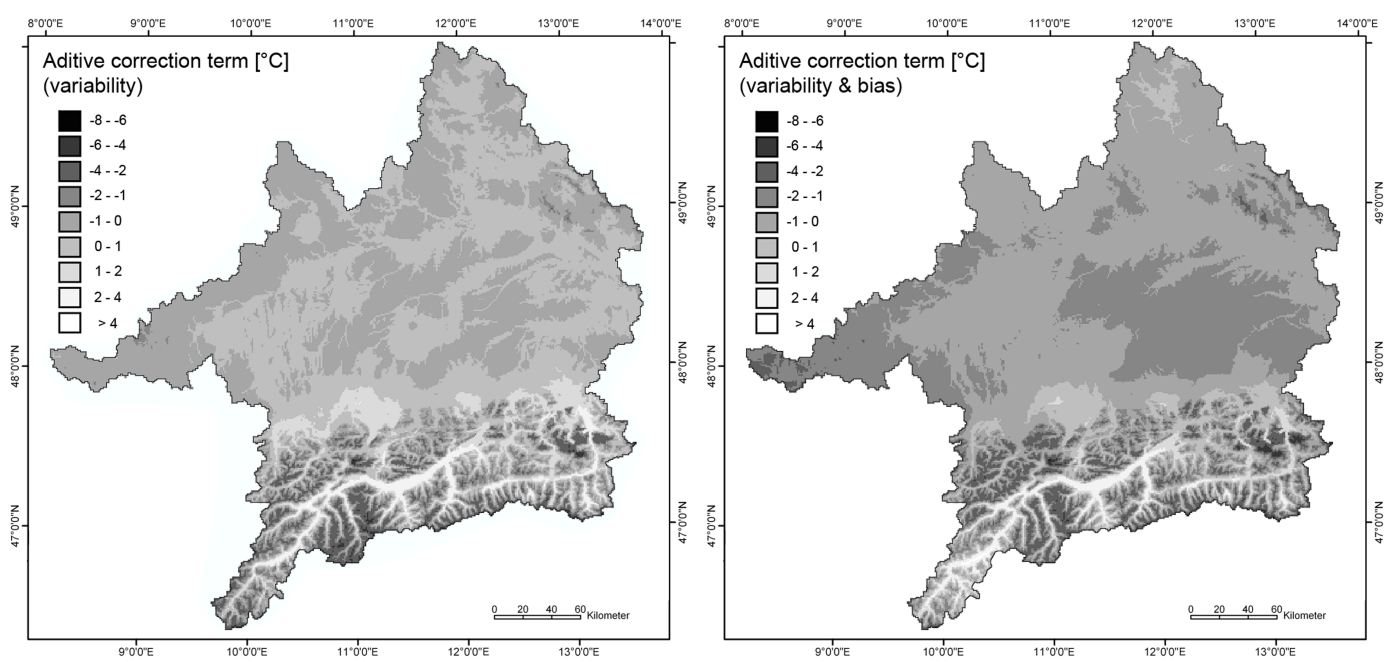

Fig. 4. Downscaling function for the correction for subgrid-scale variability (vari, $1 \times 1 \mathrm{~km})$ in MM5-simulated temperature $(45 \times 45 \mathrm{~km})$ for January (left) and function for a combined correction for subgrid-scale variability and bias (vari\&bias) in MM5-simulated temperature (ERA40 forcings) for January (right) as derived from meteorological observations and simulations for the period 1971-2000.
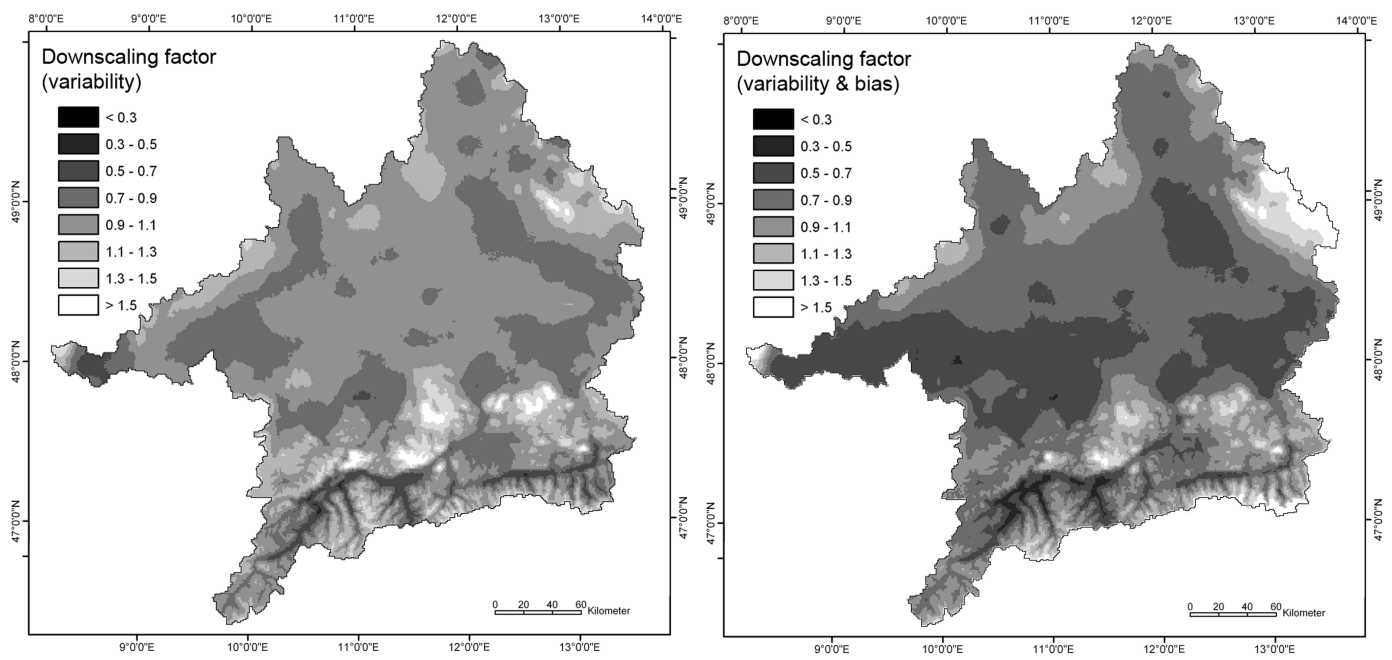

Fig. 5. Downscaling function for the correction for subgrid-scale variability (vari, $1 \times 1 \mathrm{~km})$ in MM5-simulated precipitation $(45 \times 45 \mathrm{~km})$ for January (left) and function for a combined correction for subgrid-scale variability and bias (vari\&bias) in MM5-simulated precipitation (ERA40 forcings) for January (right) as derived from meteorological observations and simulations for the period 1971-2000.

out in order to eliminate unrealistic values in the remapping results (relative humidity values above $100 \%$ are reduced to $100 \%)$.

The downscaling of temperature follows a very similar approach, with the difference that the multiplicative correction is substituted by an additive correction term. This corresponds more appropriately to the nature of the systematic (i.e. first-order linear) relation between temperature and terrain elevation. To derive the corresponding downscaling function, the multiplication and division in Eqs. (1)-(3) is simply replaced by addition and subtraction respectively. While such additive correction would be feasible for the downscaling of most meteorological parameters, a multiplicative correction circumvents the generation of negative values in case of precipitation on the one hand, and avoids the production of precipitation in those cases where the RCM simulates dry conditions on the other hand. Hence, the choice between additive and multiplicative correction has been made taking into account the physical characteristics and constraints of the different meteorological parameters.

Figure 4 shows the downscaling function in form of an additive correction for subgrid-scale variability (left) and a combined correction for subgrid-scale variability and bias (right) of MM5-simulated temperature (ERA40 forcings) 

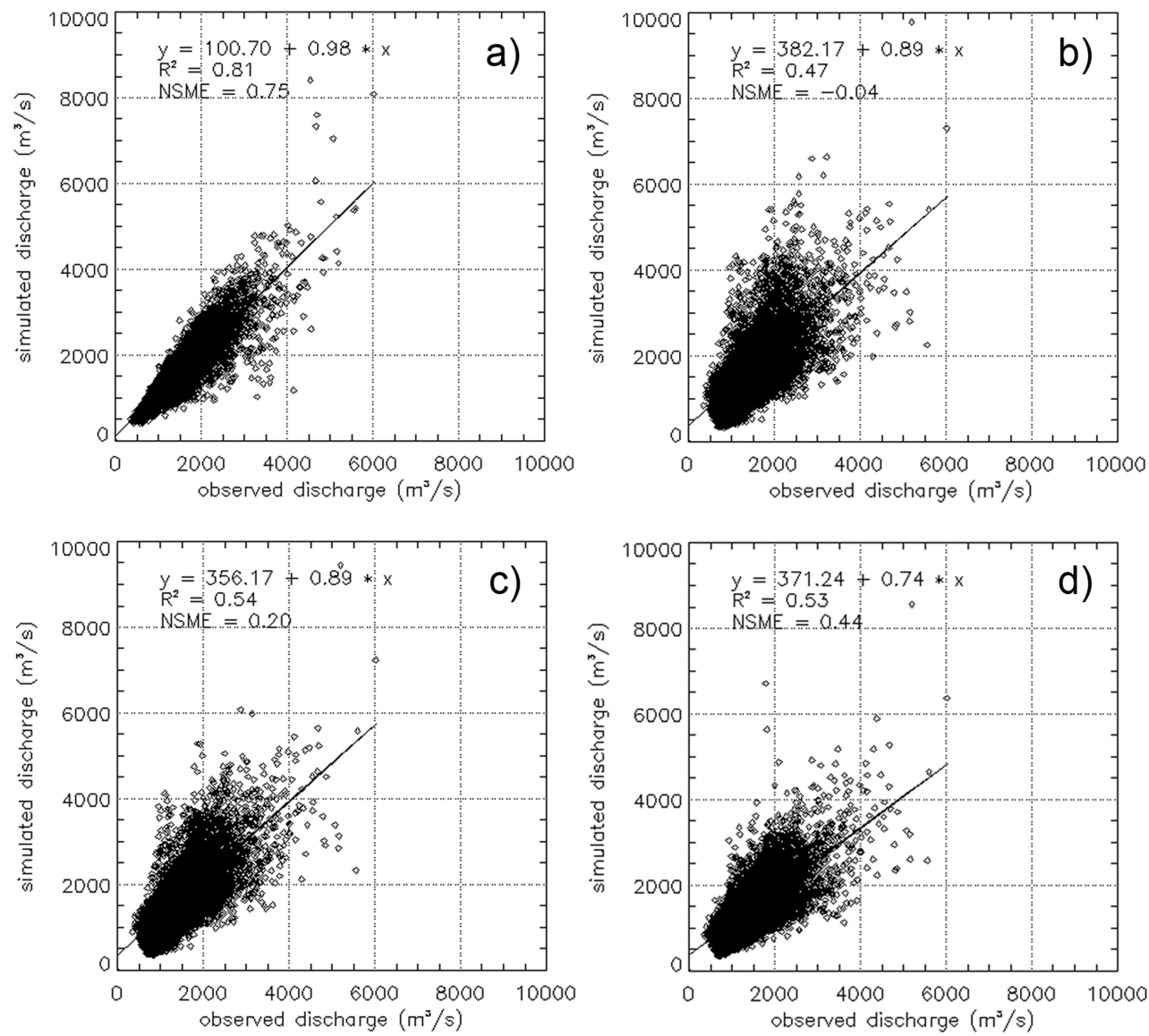

Fig. 6. Simulated versus observed daily discharge according to hydrological simulations driven by (a) meteorological observations, (b) bilinearly interpolated MM5 simulations (bil), (c) downscaled MM5 simulations (vari) and (d) downscaled and bias corrected MM5 simulations (vari\&bias) 1972-2000. The MM5 simulations are driven with ERA40 reanalysis data, the discharge simulations for the downscaling approaches vari and vari\&bias have been conducted in two separate model runs (cross-validation) to avoid "in-sample" evaluation.

exemplarily for January. This month is characterized by a rather large correction of the temperature simulations for the Upper Danube Watershed due to a mean overestimation in the MM5 simulations of $+0.8^{\circ} \mathrm{C}$. As illustrated, the combined correction for subgrid-scale variability and bias, compared to the correction for subgrid-scale variability alone, significantly reduces the simulated temperature in large parts of the Alpine foreland, whereas temperatures in the southern part of the Alps slightly increase. Both approaches induce altitudinal gradients in the remapping results by increasing temperatures in the Alpine valleys and reducing temperatures in the higher elevated parts of the Alps. In case of hydrological applications, particularly the simulation of snow water storage can be expected to benefit from this more realistic description of temperature distributions in the catchment.

The downscaling factors for the remapping of precipitation are shown in Fig. 5, again exemplarily for January. The factors for a correction for subgrid-scale variability (left) and those for a combined correction for subgrid-scale variability and bias (right) are characterized by similar correction pat- terns, increasing precipitation in higher altitudes and at the northern rim of the Alps and reducing simulated precipitation in the lower elevations of the inner Alpine valleys. Other than vari, vari\&bias corrects the comparatively small overestimation of precipitation in the MM5 simulations for January $(+12 \mathrm{~mm})$ by reducing precipitation at the catchment scale.

The spatial statistics resulting from a remapping of ERA40-driven MM5 simulations by utilization of the different downscaling approaches are summarized for the mean conditions in the Upper Danube Watershed (1971-2000) in Table 1. For all meteorological variables a shift of minimum and maximum values towards lower and higher values respectively can be observed when comparing the downscaling approaches vari and vari\&bias to a bilinear interpolation (bil). The standard deviation (StdDev) further proves that spatial variability is increased by an application of vari and vari\&bias in case of all meteorological parameters considered. While mean values are mostly identical in case of bil and vari (small deviations occur as the conservation of mass and energy using vari applies to the RCM pixel 
Table 1. Spatial statistics of the downscaled ERA40-driven MM5 simulations $(1 \times 1 \mathrm{~km})$ for the Upper Danube Watershed derived from mean values of the period 1971-2000. The abbreviations represent the mean value (Mean), the minimum value (Min), the maximum value (Max) and the standard deviation (StdDev).

\begin{tabular}{llllll}
\hline Parameter & Downscaling & Mean & Min & Max & StdDev \\
\hline \multirow{3}{*}{ Temperature [K] } & bil & 279.8 & 272.5 & 281.9 & 2.3 \\
& vari & 279.7 & 267.1 & 282.3 & 2.8 \\
& vari\&bias & 279.7 & 267.9 & 282.6 & 2.4 \\
\hline \multirow{2}{*}{ Precipitation [mm] } & bil & 1137.1 & 775.7 & 1720.8 & 236.1 \\
& vari & 1129.7 & 679.0 & 2499.6 & 295.1 \\
& vari\&bias & 1044.0 & 613.6 & 2601.6 & 333.1 \\
\hline \multirow{3}{*}{ Air humidity [\%] } & bil & 84.6 & 81.7 & 87.0 & 1.2 \\
& vari & 84.6 & 58.2 & 92.7 & 3.3 \\
& vari\&bias & 81.6 & 56.8 & 92.2 & 3.3 \\
\hline \multirow{2}{*}{ Wind speed [m s ${ }^{-1}$ ] } & bil & 3.8 & 3.1 & 4.7 & 0.3 \\
& vari & 3.8 & 1.1 & 11.2 & 0.7 \\
& vari\&bias & 2.6 & 0.8 & 7.5 & 0.6 \\
\hline
\end{tabular}

areas and not necessarily to the catchment area) vari\&bias reduces/increases the mean value depending on the biases in the RCM simulations. This effect is particularly distinct in case of precipitation, where the overestimation in MM5simulated precipitation is corrected by a reduction of area mean precipitation to $1044 \mathrm{~mm}$. While small biases in simulated temperature exist on a monthly basis that are corrected using the approach vari\&bias, annual mean temperatures in the Upper Danube Watershed are almost identical according to the results of all downscaling approaches applied.

For the hydrological evaluation of the presented downscaling approaches, the statistical downscaling of vari and vari\&bias is combined with a physically based approach used for the downscaling of surface pressure, which is also required as input for the hydrological model. The method is based on the hydrostatic approximation and ideal gas law, it's application for the remapping from coarse to fine grids is described in detail by Cosgrove et al. (2003). As recordings of incoming longwave and shortwave radiation are scarcely available, no statistical downscaling is carried out for these meteorological parameters. Instead, these parameters are bilinearly interpolated to the fine grid in case of all coupled model runs presented in this paper.

\section{Results}

The simulation results of the hydrometeorological model chain achieved with application of the statistical downscaling functions vari and vari\&bias are shown in Fig. 6 together with the results obtained by using bilinearly interpolated MM5 simulations as well as meteorological observations as meteorological drivers for PROMET. The period 1971-2000 has been splitted into two 15-yr periods to eval- uate the downscaling functions "out-of-sample". While one half is used for the generation of the downscaling functions, the other is used for their application in the hydrometeorological model chain. Hydrological simulations for the whole period 1971-2000 have been achieved by alternately using both 15-yr periods for the generation and the application of the downscaling functions. For each 15 -yr period a spin-up time of $1 \mathrm{yr}$ has been provided to the hydrological model. In combination with the fact that the MM5 data required as meteorological input has been generated only for the time period 1971-2000, this spin-up time reduces the time period considered in the subsequent hydrological evaluation to the years 1972-2000.

As Fig. 6a unfolds, PROMET driven by meteorological observations simulates daily discharge at gauge Achleiten with very good accuracy. The two effeciency criteria considered in this evaluation are the coefficient of determination $\left(R^{2}\right)$, as well as the Nash-Sutcliffe model efficiency (NSME) (Nash and Sutcliffe, 1970). NSME is defined as one minus the sum of the absolute squared differences between the predicted values (here: simulated discharge volumes $\mathrm{Q}_{\text {sim }}$ ) and the observed values (here: observed discharge volumes Qobs), normalized by the variance of the observed values:

$\mathrm{NSME}=1-\frac{\sum_{i=1}^{n}\left(\mathrm{Q}_{\mathrm{obs}}^{i}-\mathrm{Q}_{\mathrm{sim}}^{i}\right)^{2}}{\sum_{i=1}^{n}\left(\mathrm{Q}_{\mathrm{obs}}^{i}-\overline{\mathrm{Q}_{\mathrm{obs}}}\right)^{2}}$

It takes values ranging from 1 (perfect fit) to $-\infty$, with a NSME of $<0$ indicating that the mean value of the observations is a better predictor than the model. Both efficiency criteria with values of 0.81 and 0.75 for $R^{2}$ and NSME respectively, justify the conclusion that PROMET is capable 
Table 2. Performance of the hydrological model PROMET using ERA40-driven MM5 simulations in combination with different downscaling approaches as meteorological input. The two model setups represent the cross-validation experiment (two separate model runs: (i) 19711985, (ii) 1986-2000) and the "in-sample" application of the downscaling approaches (one model run: 1971-2000). All statistical criteria have been calculated on the basis of the daily discharge conditions 1972-2000 to provide the hydrological model a spin-up time of one year.

\begin{tabular}{|c|c|c|c|c|c|}
\hline Model setup & Downscaling & NSME & $R^{2}$ & Slope & Intercept \\
\hline $\begin{array}{l}\text { Combined results of two separate model runs (cross-validation): } \\
\text { (i) Hydrological simulations 1971-1985 }\end{array}$ & bil & -0.04 & 0.47 & 0.89 & 382.17 \\
\hline $\begin{array}{l}\text { (downscaling functions derived from meteorological data } \\
\text { 1986-2000) }\end{array}$ & vari & 0.20 & 0.54 & 0.89 & 356.17 \\
\hline $\begin{array}{l}\text { (ii) Hydrological simulations } 1986-2000 \\
\text { (downscaling functions derived from meteorological data } \\
\text { 1971-1985) }\end{array}$ & vari\&bias & 0.44 & 0.53 & 0.74 & 371.24 \\
\hline Results of one continuous model run 1971-2000 & bil & -0.04 & 0.47 & 0.89 & 382.17 \\
\hline (downscaling functions derived from meteorological data & vari & 0.20 & 0.54 & 0.89 & 356.74 \\
\hline $1971-2000)$ & vari\&bias & 0.42 & 0.51 & 0.74 & 376.14 \\
\hline
\end{tabular}

of simulating daily water fluxes in the watershed with only small biases over a climatological period of time.

Figure $6 \mathrm{~b}$ shows the results obtained when using bilinearly interpolated MM5 simulations to run PROMET. $R^{2}$ with 0.47 is significantly lower than that of the observationdriven model run. The value of NSME with -0.04 even indicates that the mean value of all discharge observations would have been a better predictor than the model system. The correction for subgrid-scale variability (vari) improves the quality of the hydrological simulations and leads to an $R^{2}$ of 0.54 and a NSME of 0.2 . The additional correction of biases in the RCM simulations slightly reduces the value of $R^{2}$ to 0.53 , but the NSME of 0.44 indicates an enhanced accuracy in simulated discharge. This can be explained by the fact that $R^{2}$ merely considers the covariance of discharge observations and simulations but not the difference between the observed and predicted discharge volumes. As a result, $R^{2}$ can take high values even if the performance in terms of an exact reproduction of discharge volumes is poor.

As the Fig. 6c, d further show, the number of outliers, in particular those with extremely high values of simulated discharge, is strongly reduced in case of vari and vari\&bias. These circumstances suggest that the applied multiplicative correction of RCM-simulated precipitation does not negatively affect the simulation of discharge extremes. To further investigate into this assumption, observed and simulated daily discharge have been divided into discharge classes with a class width of $300 \mathrm{~m}^{3} \mathrm{~s}^{-1}$ (see Fig. 7). As the bar plot shows, the downscaling approaches bil and vari lead to an underestimation of discharge volumes between 600 and $1800 \mathrm{~m}^{3} \mathrm{~s}^{-1}$ that is followed by an overestimation of volumes $>1800 \mathrm{~m}^{3} \mathrm{~s}^{-1}$. This overestimation of discharge in higher discharge ranges can be explained by an overestimation in MM5-simulated precipitation for the months of April and May. If not corrected, this additional rainfall further in- creases river discharge, which is already high due to significant snow melt contributions at this time of the year. The bias correction in the downscaling approach vari\&bias strongly reduces the deviations from observed discharge conditions in both low and high discharge ranges. Considering mean discharge at gauge Achleiten 1972-2000 as well as the associated standard deviation, a continous improvement can be observed from a simple bilinear interpolation (bil) over a correction for subgrid-scale variability (vari) up to the additional correction of biases in the RCM data (vari\&bias).

Figure 8 shows the model performance for the different downscaling approaches separately for the different months of the year. Comparing the results of bilinear interpolation (bil) to those achieved using the approaches vari and vari\&bias, both efficiency criteria reveal largest improvements in simulated discharge in case of the months April and May. As discussed earlier, discharge in the Upper Danube Watershed during these months is largely controled by snow melt. Hence, these improvements seem to be related to a more accurate description of snow-hydrological processes in PROMET, resulting from a more realistic representation of the spatial variability of temperatures in the catchment. In case of vari\&bias, part of the observed improvements can further be attributed to the reduction of runoff-available water due to a correction of the overestimation found in MM5simulated precipitation for the months April and May.

Averaging the monthly performance over all months of the year leads to mean values of $R^{2}$ that compare well to those presented in Fig. 6. These findings seem particularly important, as the seasonal variability in observed and simulated discharge can induce a certain bias in the results of a statistical analysis for the case that merely the correlation of daily discharge over several years is considered and the seasonal variations are not excluded from the analysis. Here, the statistical analysis in Fig. 6 seems to adequately represent the 


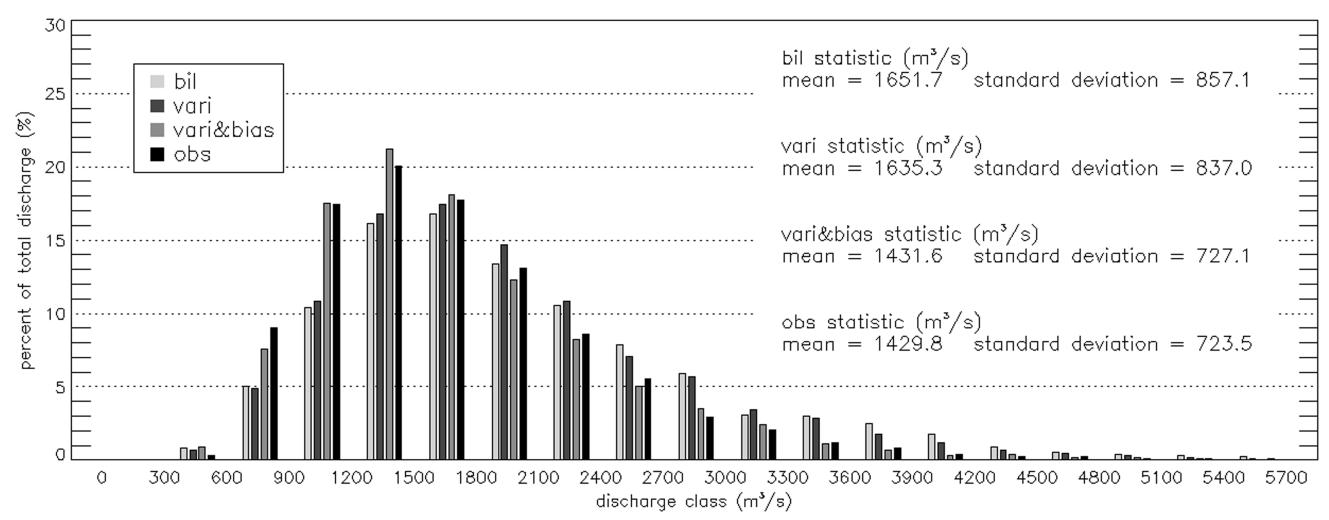

Fig. 7. Percentage of total discharge in different discharge ranges (class width $=300 \mathrm{~m}^{3} \mathrm{~s}^{-1}$ ) according to observations and the simulations of the cross-validation experiment (1972-2000).
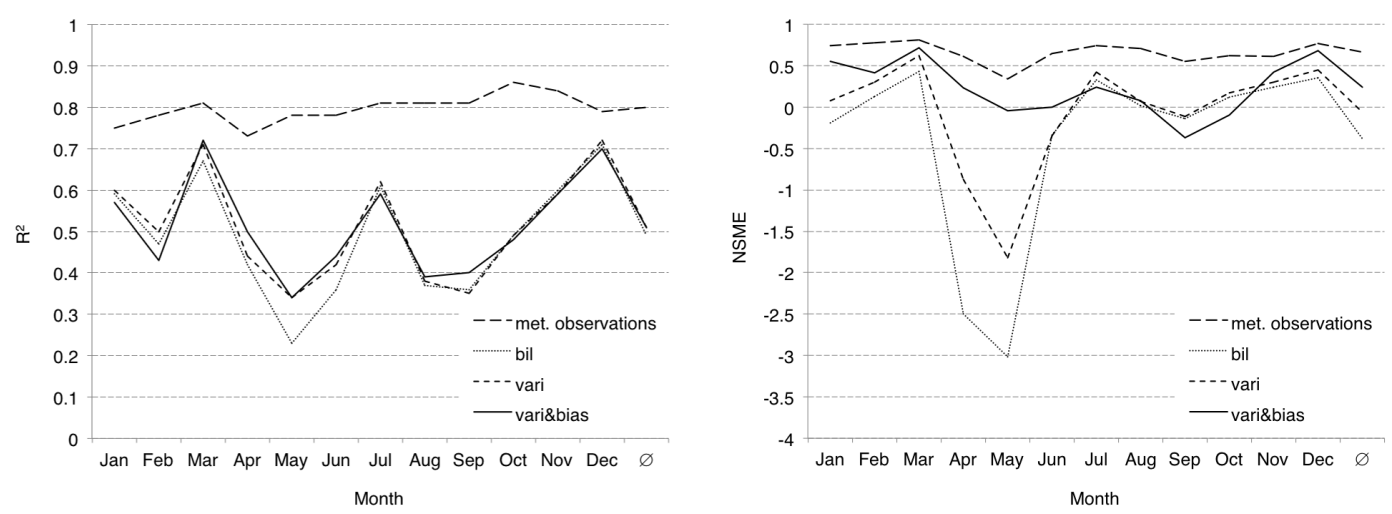

Fig. 8. Performance of the hydrological model PROMET (left: $R^{2}$, right: NSME) for the different months of the year using meteorological observations and ERA40-driven MM5 simulations in combination with different downscaling approaches as meteorological input. The discharge simulations for the downscaling approaches vari and vari\&bias have been conducted in two separate model runs (cross-validation) to avoid "in-sample" evaluation. All statistical criteria have been calculated on the basis of the daily discharge conditions 1972-2000 to provide the hydrological model a spin-up time of one year.

overall accurancy associated to the simulation of daily discharge with no or little bias induced by seasonal variations in simulated and observed discharge.

A comparison of the results of the cross-validation experiment to the results generated in an "in-sample" model run, where the whole $30-\mathrm{yr}$ period is used for the generation and the application of the presented downscaling techniques, is given in Table 2. The values of the different efficiency criteria as well as the parameters of the regression functions indicate that the results of the different approaches are characterized by neglectable differences. These findings suggest that the spatial patterns in the observation-based meteorology as well as those of the biases in the RCM data are temporally constant in the catchment considered. As a result, the performance of the downscaling techniques applied in our study seems to be very robust and shows only little dependence on the period utilized for the generation of the downscaling functions. Despite all improvements in simulated dis- charge, the application of the downscaling functions vari and vari\&bias did not reach the overall accuracy found in case of the observation-driven PROMET run (see Figs. 6 and 8).

\section{Conclusions}

A pragmatic approach for the downscaling of RCMsimulated precipitation, temperature, humidity and wind speed has been investigated in the framework of this paper in the context of hydrological modelling. The method gives the option to (i) only correct for subgrid-scale variability and conserve mass and energy between the model scales or (ii) to include a bias correction into the downscaling process. As the approach is based on multiplicative or additive corrections it is computationally inexpensive and can be applied during runtime of a coupled model system. The method has been evaluated by comparison of daily discharge recordings 
to the simulations of a hydrometeorological model chain for the period 1972-2000 at the gauge of the Upper Danube Watershed in Achleiten. The results of this comparison prove that the downscaling approaches are capable of improving the performance of the hydrological model compared to the use of bilinearly interpolated MM5 simulations. Best results have been achieved when a bias correction is included into the downscaling process. The performance of the presented methods has been separately evaluated "in-sample" and "outof-sample" (cross-validation). Comparing the results of these different approaches showed very robust overall performance and, in case of the catchment considered, only little dependence on the time period applied for the generation of the downscaling functions.

Compared to a model run using meteorological site measurements instead of downscaled RCM data as input for the hydrological model, the RCM input leads to persistent deviations from the runoff measurements at Achleiten. These differences cannot be traced back to biases in precipitation, temperature, humidity and wind speed on a monthly basis. They can only be induced by differences in the temporal dynamics between the RCM data and the meteorological observations (e.g. rainfall intensities), by short-term differences in the meteorological fields, by differences in meteorological parameters that are not affected by the correction of biases (shortwave radiation, longwave radiation) or by an interaction of different hydrometeorological parameters. Additional studies are planned for the near future to further investigate these hypotheses. In the current model setup, part of the remaining inaccuracies in simulated discharge can be explained by the fact that the observation-based meteorology of the ERA40 reanalysis influences the RCM simulations only every $6 \mathrm{~h}$ at the boundaries of the RCM domain. Other than in the "weather forecasting mode", this "climate mode" does not include any reinitialization with observation-based data for the whole model domain. The spatial patterns and temporal dynamics within the RCM domain will hence never reproduce exactly the observed temporal evolution of the smallscale meteorological conditions in the catchment. Furthermore, our downscaling approach developed to reproduce climatological means of hydrological key variables is expected to perform even better when validating on a monthly rather than on a very demanding daily time basis.

The authors want to point out that the statistical downscaling methods presented in this study, like most other statistical approaches, depend on the availability of long and comprehensive observational data records to be used for the training of the statistical model. While this prerequisite is reasonably fulfilled for the Upper Danube Catchment, it is conceivable that areas characterized by less densely available and/or less accurate meteorological station observations might yield less or even negative improvement by an application of the presented methodology.

As this study only considers MM5 simulations with a horizontal resolution of $45 \times 45 \mathrm{~km}$ driven by the global bound- ary conditions of the ERA40 reanalysis, further studies will be needed to investigate the relative effects of global boundary conditions, different approaches of dynamical regionalization and various RCM grid resolutions on the results of impact models. A follow-up study is planned to answer these research questions. The performance of the presented methods in basins located in other geographical regions, with different topographic characteristics and/or smaller catchment size represents an interesting research question to be investigated in the framework of future research activities.

The ultimate goal of our studies consists in applying the downscaling techniques pesented here on the basis of a present day training period to future climate scenarios as suggested by the IPCC.

Acknowledgements. The authors thank the German Ministry for Education and Research, the Free State of Bavaria and the LudwigMaximilians University Munich for funding the GLOWA-Danube project. Thanks also go to the German and Austrian Weather Services for providing the meteorological data used in this study.

Edited by: W. Hazeleger

\section{References}

Bach, H., Mauser, W., and Schneider, K.: The use of radiative transfer models for remote sensing data assimilation in crop growth models, in: Precis. Agric., edited by: Stafford, J., Werner, A., 35-40, ISBN:9076998213, 2003.

Cosgrove, B. A., Lohmann, D., Mitchell, K. E., Houser, P. R., Wood, E. F., Schaake, J. C., Robock, A., Marshall, C., Sheffield, J., Duan, Q., Luo, L., Higgins, R. W., Pinker, R. T., Tarpley, J. D., and Meng, J.: Real-time and retrospective forcing in the North American Land Data Assimilation System (NLDAS) project, J. Geophys. Res., 108, doi:10.1029/2002JD003118, 2003.

Daly, C., Neilson, R. P., and Phillips, D. L.: A statisticaltopographic model for mapping climatological precipitation over mountainous terrain, J. Appl. Meteorol., 33, 140-158, 1994.

Frei, C. and Schär, C.: A precipitation climatology of the Alps from high-resolution rain-gauge observations, Int. J. Climatol., 18, 873-900, 1998.

Früh, B., Schipper, J. W., Pfeiffer, A., and Wirth, V.: A pragmatic approach for downscaling precipitation in alpine-scale complex terrain, Meteorol. Z., 15 (6), 631-646, 2006.

Früh, B., Bendix, J., Nauss, T., Paulat, M., Pfeiffer, A., Schipper, J. W., Thies, B., and Wernli, H.: Verification of precipitation from regional climate simulations and remote-sensing observations with respect to ground-based observations in the upper Danube catchment, Met. Z., 16, 275-293, 2007.

Fowler, H. J., Blenkinsop, S., and Tebaldi, C.: Review: Linking climate change modelling to impacts studies: Recent advances in downscaling techniques for hydrological modelling, Int. J. Climatol., 27, 1547-1578, 2007.

Gerstengarbe, F.-W. and Werner, P. C.: Katalog der Großwetterlagen Europas (1881-1998), Potsdam-Institut für Klimafolgenforschung, DWD, 1999. 
Grell, G. A., Dudhia, J., and Stauffer, D. R.: A description of the fifth-generation Penn State/NCAR mesoscale model (MM5), NCAR/TN-398+STR, 1994.

Hagemann, S., Botzet, M., and Machenhauer, B.: The summer drying problem over south-eastern Europe: sensitivity of the limited area model HIRHAM4 to improvements in physical parameterization and resolution,. Phys. Chem. Earth, 26, 391-396, 2001.

Hank, T., Oppelt, N., and Mauser, W.: Physically based modelling of photosynthetic processes, in: Stafford, J. V.: Precision Agriculture '07, 165-172, Wageningen, The Netherlands, 2007.

Jacob, D., Bärring, L., Christensen, O.B., Christensen, J.H., de Castro, M., Déqué, M., Giorgi, F., Hagemann, S., Hirschi, M., Jones, R., Kjellström, E., Lenderink, G., Rockel, B., Sánchez, E., Schär, C., Seneviratne, S.I., Somot, S., van Ulden, A., and van den Hurk, B.: An inter-comparison of regional climate models for Europe: model performance in present-day climate, Climatic Change, 81, 31-52, 2007.

Kotlarski, S., Block, A., Bhm, U., Jacob, D., Keuler, K., Knoche, R., Rechid, D., and Walter, A.: Regional climate model simulations as input for hydrological applications: evaluation of uncertainties, Adv. Geosci., 5, 119-125, doi:10.5194/adgeo-5-1192005, 2005.

Lazar, B. and Williams, M.: Climate change in western ski areas: Potential changes in the timing of wet avalanches and snow quality for the Aspen ski area in the years using vari applies to the 2030 and 2100, Cold Reg. Sci. Technol., 51, 219-228, 2008.

Leung, L. R., Qian, Y., Bian, X., Washington, W. M., Han, J., and Roads, J. O.: Mid-Century Ensemble Regional Climate Change Scenarios for the Western United States, Climatic Change, 62, 75-113, 2004.

Liston, G. E. and Elder, K.: A Meteorological Distribution System for High-Resolution Terrestrial Modeling (MicroMet), J. Hydrometeorol., 7, 217-234, 2006.

Ludwig, R. and Mauser, W.: Modelling catchment hydrology within a GIS based SVAT-model framework, Hydrol. Earth Syst. Sci., 4, 239-249, doi:10.5194/hess-4-239-2000, 2000.

Marke, T.: Development and Application of a Model Interface to couple Regional Climate Models with Land Surface Models for Climate Change Risk Assessment in the Upper Danube Watershed, Ph.D. thesis, Department of Geography, LudwigMaximilians University, Munich, Germany, 2008.

Mauser, W. and Bach, H.: PROMET - a Physically Based Hydrological Model to Study the Impact of Climate Change on the Water Flows of Medium Sized, Mountain Watersheds, J. Hydrol., 376, 362-377, doi:10.1016/j.hydrol.2009.07.046, 2009.

Mauser, W. and Schädlich, S.: Modeling the Spatial Distribution of Evapotranspiration on Different Scale using Remote Sensing Data, J. Hydrol. (Special BAHC Issue), 212-213, 1998.

Murphy, J.: An evaluation of statistical and dynamical techniques for downscaling local climate, J. Climate, 12, 2256-2284, 1999.

Nash, J. E. and Sutcliffe, J. V.: River flow forecasting through conceptual models, a discussion of principles, J. Hydrol., 10, 282290,1970
Pfeiffer, A. and Zängl, G.: Validation of climate-mode MM5simulations for the European Alpine Region, Theor. Appl. Climatol., 101, 93-108, 2010.

Schipper, J. W., Früh, B., Pfeiffer, A., and Zängl, G.: Wind Direction-Dependent Statistical Downscaling of Precipitation Applied to the Upper Danube Catchment, Int. J. Clim., doi:10.1002/joc.2084, 1-14, 2010.

Sevruk, B.: Systematischer Niederschlagsmessfehler in der Schweiz, in: Der Niederschlag in der Schweiz, edited by: Sevruk, B., Beiträge zur Geologie der Schweiz - Hydrologie, 31, 65-75, 1985.

Strasser, U. and Mauser, W.: Modelling the spatial and temporal variations of the water balance for the Weser catchment 19651994, J. Hydrol., 254 (1-4), 199-214, 2001.

Uppala, S. M., Kållberg, P. W., Simmons, A. J., Andrae, U., da Costa Bechtold, V., Fiorino, M., Gibson, J. K., Haseler, J., Hernandez, A., Kelly, G. A., Li, X., Onogi, K., Saarinen, S., Sokka, N., Allan, R. P., Andersson, E., Arpe, K., Balmaseda, M. A., Beljaars, A. C. M., van de Berg, L., Bidlot, J., Bormann, N., Caires, S., Chevallier, F., Dethof, A., Dragosavac, M., Fisher, M., Fuentes, M., Hagemann, S., Hólm, E., Hoskins, B. J., Isaksen, V., Janssen, P. A. E. M., Jenne, R., McNally, A. P., Mahfouf, J.-F., Morcrette, J.-J., Rayner, N. A., Saunders, R. W., Simon, P., Sterl, A., Trenberth, K. E., Untch, A., Vasiljevic, D., Viterbo, P., and Woollen, J.: The ERA-40 reanalysis. Q. J. Roy. Meteor. Soc., 131, 2961-3012, doi:10.1256/qj.04.176, 2005.

Watts, M., Goodess, C. M., and Jones, P. D.: The CRU Daily Weather Generator. BETWIXT Technical Briefing Note 1, Climatic Research Unit, University of East Anglia, 2004.

Wege, C.: Regionalisierung der aktuellen Verdunstung auf der Mesoskala mit Flächenparametern aus Fernerkundungsdaten, Ph.D. thesis, Department of Geography, Ludwig-Maximilians University, Munich, Germany, 1998.

Widmann, M., Bretherton, C. S., and Salathé Jr, E. P.: Statistical Precipitation Downscaling over the Northwestern United States Using Numerically Simulated Precipitation as a Predictor, J. Climate, 16, 799-816, 2003.

Wilby, R. L. and Wigley, T. M. L.: Downscaling general circulation model output: a review of methods and limitations, Prog. Phys. Geog., 21, 530-548, 1997.

Wilby, R. L., Hay, E. L., Gutowski, W. J., Arritt, R. W., Takle, E. S., Pan, Z., Leavesley, G. H., and Clark, M. P.: Hydrological responses to dynamically an statistically downscaled climate model output, Geophys. Res. Lett., 27, 8, 1199-1202, 2000.

Wood, A. W., Leung, L. R., Sridhar, V., and Lettenmaier, D. P.: Hydrological implications of dynamical and statistical approaches to downscaling climate model outputs, Climatic Change, 62, 189-216, 2004. 